\title{
The semi-Markov model of energy state changes of the main marine internal combustion engine and method for evaluating its operation during ship voyage
}

Jerzy Girtler, Prof.

Gdansk University of Technology

\section{ABSTRACT}

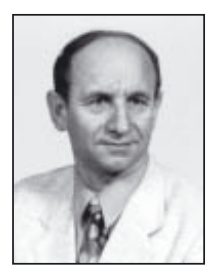

The article presents a method for evaluating the operation of internal combustion engines used as the main engines in the propulsion systems of sea-going ships in various operating conditions. This method enables calculating the engine operation value based on the theory of semi-Markov processes and mathematical statistics. What is noteworthy, the operation of the examined internal combustion engines is compared to a physical quantity which is expressed in the form of a number with the measure unit called joule-second. a model having the form of a semi-Markov process is proposed to describe the energy state changes taking place in the main engines during their operation. Also proposed is the use of the point and interval estimation at a given confidence level $\beta$ for determining the value of the energy converted in the engine during its operation for the known and unknown standard energy deviation treated as the random variable. The semi-Markov model of changes of the energy converted in the engine during its operation is presented in a general form. The above model was used for determining the ship's main engine operation, which is in the examined case a function of the energy converted in particular energy states, the expected value of the time of duration of these states and the probability of their existence. These probabilities compose the limiting distribution of the semi-Markov process, the values of which are the specified main engine energy states.

Key words: operation; energy; semi-Markov process; piston internal combustion engine

\section{INTRODUCTION}

References $[2,4,6,12,13]$ present a proposal to investigate the operation of internal combustion engines as the effect of the existence of their energy states which makes it possible to convert the delivered energy $\mathrm{E}$ and transmit it in time to the energy receivers, such as propeller screws, pumps, compressors, etc. For the operation understood in the above way a method was proposed to valuate the operation of diesel engines used in shipbuilding in a general formulation taking into account the engine wear [2,6]. Ref. [2] discusses the operation of the abovementioned internal combustion engines used as the main engines in the propulsion systems of sea-going ships taking into account the fact that correct operation of these engines requires securing delivery of sufficient amount of energy to its receivers, which are the propeller screws. The method presented in that article makes use of the deterministic model of engine operation which takes into account ship sailing conditions.

This article presents a stochastic model in the form of a semi-Markov process to model the changes of energy states of an arbitrary main engine, and the method for valuating the operation of those engines using this model. Like in Ref. [2], it was assumed here that the operation (D) can be compared to the physical quantity being the product of energy (E) and time (t) of its conversion, i.e. $D=E \cdot t$.
The above interpretation of the operation of piston internal combustion engines results from the application of the analogy method (the intermediate method between induction and deduction), which makes it possible to transmit the observations from one object of investigation (empirical system) to another. Like in Ref. [2], the inspirations for developing the here presented method were proposals by P. L. Maupertius and W. R. Hamilton to consider the operation of a mechanical system as a physical quantity which reflects changes of mechanical energy in time. In classical physics an interpretation of the operation can be found which considers it the effect of the change of energy in time, expressed in the form of the product of energy and time, with the joule-second (joule $\times$ second) as the resultant measure unit.

In this formulation distinction is made between the operation $[18,19]$ :

- of the mechanical system (system of material points) being the result of kinetic and potential energy changes, which is referred to as the Hamilton operation $\left(\mathrm{D}_{\mathrm{H}}\right)$ and

- resulting from the change of only the kinetic energy of the mechanical system (body), called the Maupertius operation $\left(\mathrm{D}_{\mathrm{M}}\right)$.

A similar interpretation of the operation was adopted in quantum mechanics with respect to the source of 
electromagnetic radiation [8]. There, the equivalent of the operation having a similar sense is the Planck's constant (h), which is also a physical quantity expressed by a number and the measure unit [joule $\times$ second].

Achievements in classical physics and quantum mechanics in this area were the motivations for the author to introduce the operation understood in the above way also to the technique, giving it a specific interpretation for particular power generation devices, including diesel engines. During the operation of these engines the energy conversion also takes place. The energy is first converted into heat $(\mathrm{Q})$ and then into work (L). In the former case the chemical energy collected in the fuel-air mixture is converted into the internal energy of the exhaust gas, which bears the name of the thermal energy. This process takes place during fuel combustion. In the latter case, in turn, the internal energy in the exhaust gas is converted into the mechanical (kinetic and potential) energy of the moving piston. Obviously, the above energy conversion processes are accompanied with losses.

Such an approach to engine operation seems to be more favourable, as comparing energy conversion related advantages of particular engines based solely on the analysis and evaluation of their power or work does not give comprehensive information of the engine capability to perform the task. This information can only be obtained from a combined analysis of the work and the time of its realisation, represented by the quantity $\mathrm{D}=\mathrm{L} \cdot \mathrm{t}$ or $\mathrm{D}=\mathrm{N} \cdot \mathrm{t}^{2}$, as it may happen that the engine is capable to convert the required energy to get the work $\mathrm{L}$, but the time $\mathrm{t}$ which it needs for doing this is longer than the required time (for instance, excessively long time of duration of transient processes, so-called unsteady states, in the engine before it is fully loaded). Or, it may happen that the work $\mathrm{L}=\mathrm{N} \cdot \mathrm{t}$ needed for performing the assumed task will not be done by the engine in a given time $t$ (for instance, due to excessively small power output $\mathrm{N}$ of the engine resulting from its wear). Hence the conclusion that evaluating the correctness of engine operation based only on its power or work, without simultaneously taking into account the time of engine operation, is insufficient for full assessment of its energy conversion related qualities. Obviously, the engine power is an important parameter, as it contains the information how quickly the work can be done. But the operation in the above presented formulation is also important as it contains the information how long the engine can work. Since obtaining the required work (L) via conversion of the energy (E) is accompanied by energy losses in the form of heat $(\mathrm{Q})$, therefore it is more reasonable to analyse energy changes, and not only engine work during engine operation.

The advantage of the interpretation of the diesel engine operation proposed by the author is that the earlier descriptive evaluation of engine operation, for instance: the operation is good, bad, etc., can be replaced by the assessment based on comparing the engine operation with the reference standard operation using numbers and the measure unit, which is the joule-second.

The sense of the above interpretation of the operation of an engine, and in general any power generation device, can also be justified by the observation that changes of motion of a body depend on the force (F) acting on this body and the time (t) during which this action takes place. Body's capability to move is expressed by the product of force and time $(F \cdot t)$ bearing the name of the impulse of force [9]. The measure unit of the impulse of force is the newton-second. By analogy, we can conclude that the operation (D) of the diesel engine depends on work $(\mathrm{L})$ done by this engine and time $(\mathrm{t})$ of its operation, i.e. $\mathrm{D}=\mathrm{L} \cdot \mathrm{t}$.

\section{CONDITIONS OF MAIN ENGINE OPERATION AND THEIR STOCHASTIC NATURE}

The conditions of main engine operation depend on the conditions in which it works, which are determined by external conditions of sailing of the sea-going ship and tasks undertaken by ship users (the crew). These conditions and tasks are the reason why different amounts of energy are converted in different times in the working spaces of these engines. In each case, however, the operation of the main engine is defined by the area of its performance $[2,11,16,17]$. These performance areas are determined by engine speed characteristics, including external and control characteristics. If these characteristics are projected against the propeller characteristics, which also belong to the speed characteristics, then the ranges of operation of these engines are defined $[4,5]$.

It was shown in Ref [2] that the points of cooperation for a given propeller characteristic are created depending on the injection pump setting. Therefore it may happen that along a given propeller characteristic the main engine can be loaded with power according to the following external power characteristics $[11,16,17]$ :

- external characteristic of partial power $\mathrm{N}_{\mathrm{ec}}\left(\mathrm{h}_{\mathrm{c}}=\right.$ idem, $\mathrm{c}=1,2, \ldots, \mathrm{N}_{\mathrm{ec}}<\mathrm{N}_{\mathrm{etr}}$,

- external characteristic of continuous operating power $\mathrm{N}_{\mathrm{etr}}$ $\left(h_{t r}=\right.$ idem $)$,

- external characteristic of nominal power $\mathrm{N}_{\mathrm{en}}\left(\mathrm{h}_{\mathrm{n}}=\mathrm{idem}\right)$,

- external characteristic of maximal power $\mathrm{N}_{\mathrm{emax}}\left(\mathrm{h}_{\max }=\right.$ =idem).

A sample realisation of power changes of the main engine during its operation is shown in Fig. 1 [2]. The effective power $\mathrm{N}_{\mathrm{e}}$ generated by the main engine characterises the engine operation in the aspect of the rate of energy conversion into work, taking into account various types of losses, in particular thermal loss. However, engine operation consisting in energy conversion into work is not possible if this energy is not earlier converted into heat in the engine working spaces $[2,15]$. Therefore when analysing the main engine operation we should take into account the energy delivered to the engine in the fuel-air mixture, which is first converted into heat (Q) and then into work $(\mathrm{L})$, rather then the pure engine power output.

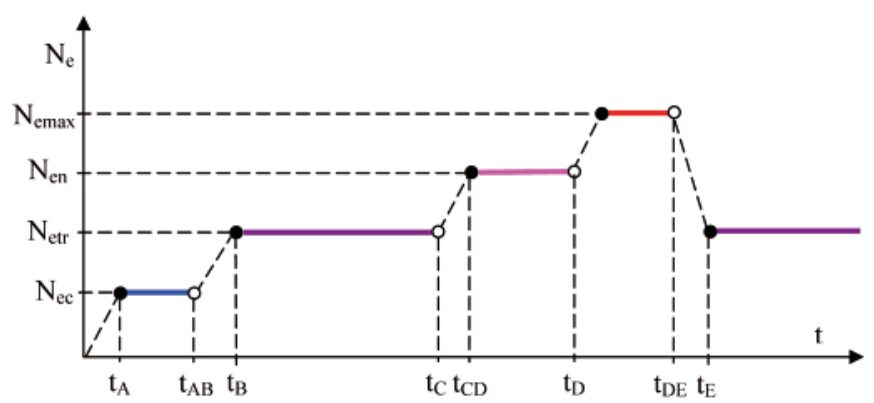

Fig. 1. Sample realisation of the process of main engine load changes during engine operation: $N_{e}$-effective power, $t$-operating time [2]

The analysis should focus on the process of changes of the energy delivered to the engine. Particular states of this process should be the energy states which release the energy $E_{j}(j=1, \ldots, 4)$, and secure the generation of particular powers $\mathrm{N}_{\mathrm{ej}}(\mathrm{j}=1, \ldots, 4)$, which are essential for correct engine operation and secure realisation of the operating task, (Fig. 1):

$$
\mathrm{N}_{1}=\mathrm{N}_{\mathrm{ec}}, \mathrm{N}_{2}=\mathrm{N}_{\mathrm{etr}}, \mathrm{N}_{3}=\mathrm{N}_{\mathrm{en}}, \mathrm{N}_{4}=\mathrm{N}_{\mathrm{emax}}
$$


The analysis can be performed using a deterministic or stochastic model for describing real main engine energy change processes.

The deterministic model of energy state changes taking place in the main engine during its operation was presented and discussed in Ref. [2]. This article presents the stochastic model of these changes having the form of a semi-Markov process.

\section{MODEL OF ENGINE OPERATION IN THE FORM OF A SEMI-MARKOV PROCESS}

Developing the model of internal combustion engine operation in the form of the semi-Markov process requires the application of the theory of semi-Markov processes. The publications on the semi-Markov processes give definitions of this process which differ by the range of generality and precision $[3,7]$. For the purpose of modelling changes of the internal combustion engine energy states the semi-Markov process (family of random variables) $\{\mathrm{X}(\mathrm{t}): \mathrm{t} \geq 0\}$ at $\mathrm{T}=[0$, $+\infty)$, can be defined using a so-called homogeneous markovian process of recovery [7].

The semi-Markov model of an arbitrary real process can be only constructed when the states of this process can be defined in such a way that the time of duration of the state existing in time $\tau_{\mathrm{n}}$ and the state which is to be obtained in time $\tau_{\mathrm{n}+1}$ do not depend stochastically on the states which earlier took place, nor the time intervals of those states.

Constructing the semi-Markov model $\{X(t): t \geq 0\}$ of the real process of energy state changes taking place in the diesel engine operation phase is possible, because [3]:

1) the Markov condition is fulfilled which says that the future evolution of an arbitrary process of the energy state changes taking place during engine operation depends solely on the engine state at a given time instant and not on the past engine operation, consequently the future state of this process and the time of its duration depend on the present and not on the past,

2) random variables $T_{i}$, which represent the time of duration of the state $e_{i}$ irrespective of the fact which state will be the next, and $\mathrm{T}_{\mathrm{ij}}$, which represent the time of duration of the state "e $\mathrm{e}_{\mathrm{i}}$ " on condition that the next state of this process is the state ,,$e_{j}$, , have distributions different than the exponential distribution.

When analysing changes of the main engine energy states $e_{i}$ resulting from converting particular energies $E_{i}(i=1, \ldots, 4)$ in the interpretation expressed by formula (1) for engine operation which enables the ship to perform the transporting task in a relatively long time, theoretically tending to infinity $(t \rightarrow \infty)$, we can omit time intervals connected with changes of energy states $e_{i}$ taking place when the energy converted in the engine working spaces increases from $E_{i}$ to $E_{i+1}$ to generate engine power output corresponding to those energies (1) in given time intervals (Fig. 1). Consecutive power outputs $\mathrm{N}_{\mathrm{ej}}(\mathrm{j}=1, \ldots, 4)$ can be considered the effects of the engine energy states $e_{j} \in E_{e}(j=1, \ldots, 4)$ of the stochastic process $\{X(t): t \geq 0\}$, each of which takes a constant values in the time interval $\left[\tau_{\mathrm{m}}, \tau_{\mathrm{m}+1}\right)$.

That means that the semi-Markov process $\{\mathrm{X}(\mathrm{t}): \mathrm{t} \geq 0\}$ is the process having the realisations constant in intervals and continuous on the right. Therefore the process is discrete in states and continuous in time. a sample fragment of the realisation $\mathrm{x}(\mathrm{t})$ of this process is shown in Fig. 2. This realisation reflects the situation when, following the elapsed time $t$, successive state changes of this process take place in successive time intervals $\left[\tau_{\mathrm{m}}, \tau_{\mathrm{m}+1}\right)$.

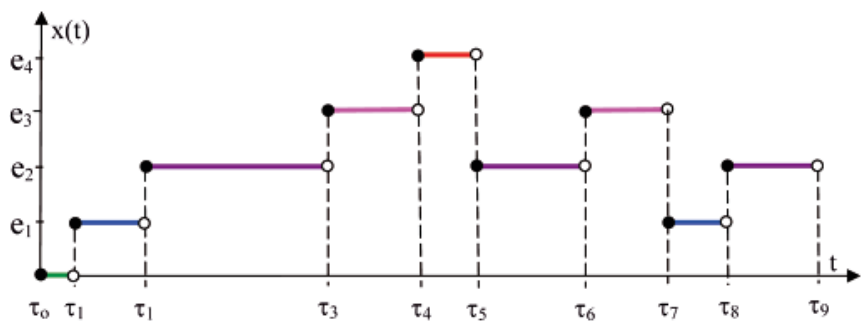

Fig. 2. Fragment of a sample realisation $x(t)$ of the semi-Markov process $\{X(t): t \geq 0\}$

In case of marine main engines, in an arbitrary time of their operation the process $\{X(t): t \geq 0\}$ can take one of the energy states existing during engine operation and belonging to the set:

$$
\mathrm{E}_{\mathrm{e}}=\left\{\mathrm{e}_{1}, \mathrm{e}_{2}, \mathrm{e}_{3}, \mathrm{e}_{4}\right\}
$$

with elements having the following interpretation (Fig. 1):

$\mathrm{e}_{1}-$ engine energy state resulting from generation of energy $\mathrm{E}_{1}$ corresponding to engine load with partial power $\mathrm{N}_{1}=\mathrm{N}_{\mathrm{ec}}$,

$\mathrm{e}_{2}-$ engine energy state resulting from generation of energy $\mathrm{E}_{2}$ corresponding to engine load with (continuous) operating power $\mathrm{N}_{2}=\mathrm{N}_{\text {etr }}$,

$\mathrm{e}_{3}-$ engine energy state resulting from generation of energy $\mathrm{E}_{3}$ corresponding to engine load with nominal power $\mathrm{N}_{3}=\mathrm{N}_{\mathrm{en}}$

$\mathrm{e}_{4}$ - engine energy state resulting from generation of energy $\mathrm{E}_{4}$ corresponding to engine load withy maximal power $\mathrm{N}_{4}=\mathrm{N}_{\mathrm{emax}}$

Making distinction between those energy states differing by engine load is important because these states originate from the principles of diesel engine operation and are connected with the need for precise positioning of the fuel lever corresponding to particular loads $[11,15,16,17]$.

According to the presented model of energy state changes in the form of the process $\{\mathrm{X}(\mathrm{t}): \mathrm{t} \geq 0\}$, an arbitrary main engine which is in state $\mathrm{e}_{1}$ during its operation can reach, due to load increase, the state $e_{2}$ with the probability $p_{12}$ after time $T_{12}$, and then reach the state $e_{3}$ with the probability $p_{23}$ after time $T_{23}$. The state $e_{4}$ of the process $\{X(t): t \geq 0\}$ will take place when an arbitrary main engine starts converting energy $\mathrm{E}_{4}$. In a similar way, from the state $\mathrm{e}_{4}$ the process can reach the state $\mathrm{e}_{3}$ with the probability $\mathrm{p}_{43}$ after time $\mathrm{T}_{43}$, or the state $\mathrm{e}_{2}$, which can take place with probability $\mathrm{p}_{42}$ after time $\mathrm{T}_{42}$, etc.

A characteristic feature of the presented model of main engine energy state changes $\{\mathrm{X}(\mathrm{t}): \mathrm{t} \geq 0\}$ is that the change of the state $e_{i}$ into the state $e_{j}$ only depends on the properties of the state $e_{i}$, and not on the previous states. This feature justifies the opinion that it is the semi-Markov process.

In this process the set of states $\mathrm{E}_{\mathrm{e}}=\left\{\mathrm{e}_{1}, \mathrm{e}_{2}, \mathrm{e}_{3}, \mathrm{e}_{4}\right\}$ is finite. The elements composing this set are the values of the semiMarkov process $X(t): t \geq 0\}$. Changes of states in this process take place at times $\tau_{0}=0, \tau_{1}, \tau_{2}, \ldots$ and after the lapse of time intervals of their duration (Fig. 2) being random variables with different distributions. The state changes in this process take place with the following probability:

$$
\begin{gathered}
\operatorname{P}\left\{X\left(\tau_{n+1}\right)=e_{j}, \tau_{n+1}-\tau_{n}<\right. \\
\left.<\mathrm{t} \mid X\left(\tau_{n}\right)=e_{i}, X\left(\tau_{n-1}\right), \ldots, X\left(\tau_{0}\right), \tau_{n}-\tau_{n-1}, \ldots, \tau_{1}, \tau_{0}\right\}= \\
=\operatorname{P}\left\{X\left(\tau_{n+1}\right)=e_{j}, \tau_{n+1}-\tau_{n}<t \mid X\left(\tau_{n}\right)=e_{i}\right\}
\end{gathered}
$$

where:

$e_{i}, e_{j} \in E_{e}, i, j=1,2,3,4 ; e_{i} \neq e_{j}$. 
As a result, when the state $\mathrm{e}_{i}(\mathrm{i}=0,1, \ldots, 4)$ of the process $\{\mathrm{X}(\mathrm{t}): \mathrm{t} \geq 0\}$ is known at time $\tau_{\mathrm{n}}$, the time of its duration and the state $e_{j}$ reached at time $\tau_{n+1}$ do not depend stochastically on the process states taking place at times $0=\tau_{0}, \tau_{1}, \ldots, \tau_{\tilde{n} 1}$, nor the time intervals of their duration.

The stochastic process $\{\mathrm{X}(\mathrm{t}): \mathrm{t} \geq 0\}$ is the process whose states are identical (constant) in intervals and the realisations of these states are continuous on the right. The lengths of the intervals $\left[\tau_{0}\right.$, $\left.\tau_{1}\right),\left[\tau_{1}, \tau_{2}\right),\left[\tau_{2}, \tau_{3}\right), \ldots,\left[\tau_{\mathrm{n}}, \tau_{\mathrm{n}+1}\right), \ldots$, in which the process $\{\mathrm{X}(\mathrm{t}): \mathrm{t}$ $\geq 0$ \} takes constant (the same) values are random variables with positive distributions. In case of the loads of the abovementioned engines we can assume [3] that the duration time of an arbitrary state $\mathrm{e}_{\mathrm{i}} \in \mathrm{E}_{\mathrm{e}}(6)$, which was reached at time $\tau_{\mathrm{n}}$ and the state reached at time $\tau_{\mathrm{n}+1}$ do not depend stochastically on the states which earlier took place, nor the time intervals of their duration. Consequently, the process $\{\mathrm{X}(\mathrm{t}): \mathrm{t} \geq 0\}$ is the model of randomly changing main engine loads, with the set of states $E_{\mathrm{e}}=\left\{\mathrm{e}_{1}, \mathrm{e}_{2}, \mathrm{e}_{3}\right.$, $\left.\mathrm{e}_{4}\right\}$ and the graph of state changes shown in Fig. 3.

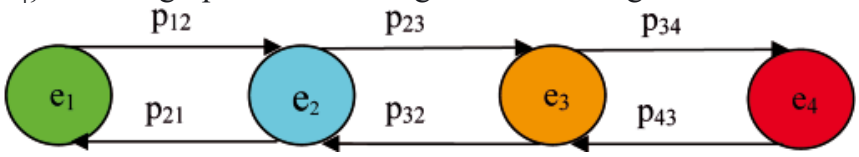

Fig. 3. Graph of state changes in the process $\{X(t): t \geq 0\}$

The specified states $e_{i} \in E_{e}(i=1,2,3,4)$ of the process $\{X(t): t \geq 0\}$ of an arbitrary main engine can be recognised using relevant diagnostic systems (SD), the applicability of which depends on the quality of the adopted diagnosing system (SDG) and its capability to recognise the states of the abovementioned engines as the diagnosed systems (SDN).

During the operation of an arbitrary diesel engine working as the main engine, changes of the states belonging to the set $\mathrm{E}_{\mathrm{e}}=\left\{\mathrm{e}_{\mathrm{i}} ; \mathrm{i}=1,2,3,4\right\}$ can be interpreted as the process $\{X(t): t \geq 0\}$ with the realisations constant (identical) in consecutive time intervals and continuous on the right $[3,7]$. The lengths of the intervals in which the process $\{\mathrm{X}(\mathrm{t}): \mathrm{t} \geq 0\}$ takes the constant (identical) values are the random variables $\mathrm{T}_{\mathrm{ij}}$ representing the time of duration of the state $\mathrm{e}_{\mathrm{i}} \in \mathrm{E}$ of this process, on condition that the next state is $e_{j} \in E_{e}$, where $\mathrm{i}, \mathrm{j}=1, \ldots, 4$ and $\mathrm{i} \neq \mathrm{j}$. These variables are independent random variables with finite expected values $E\left(\mathrm{~T}_{\mathrm{ij}}\right)$ and have positively concentrated distributions. Moreover, this process reveals a property consisting in the fact that the duration time of the state $\mathrm{e}_{\mathrm{i}}$ which took place at time $\tau_{\mathrm{n}}$ and the state which started at time $\tau_{n+1}$ do not depend stochastically on the states which took place earlier, nor the time intervals of their duration. Therefore we can assume that the future states (situations) depend solely on the presently existing situation. That means that the process $\{\mathrm{X}(\mathrm{t}): \mathrm{t} \geq 0\}$ is the semi-Markov process with the state change graph shown in Fig. 3. Defining this process requires defining its initial distribution $P_{i}$ and the functional matrix $Q(t)$.

The initial distribution of the process $\{\mathrm{X}(\mathrm{t}): \mathrm{t} \geq 0\}$ is the following:

$$
P_{i}=P\left\{X(0)=e_{i}\right\}=\left\{\begin{array}{l}
1 \text { for } i=0 \\
0 \text { for } i=1,2, \ldots, 3
\end{array}\right.
$$

According to the state change graph shown in Fig. 3, the functional matrix has the following form:

$$
\mathrm{Q}(\mathrm{t})=\left[\begin{array}{cccc}
0 & \mathrm{Q}_{01}(\mathrm{t}) & 0 & 0 \\
\mathrm{Q}_{10}(\mathrm{t}) & 0 & \mathrm{Q}_{12}(\mathrm{t}) & 0 \\
0 & \mathrm{Q}_{21}(\mathrm{t}) & 0 & \mathrm{Q}_{23}(\mathrm{t}) \\
0 & 0 & \mathrm{Q}_{32}(\mathrm{t}) & 0
\end{array}\right]
$$

The elements of the matrix (5) are non-decreasing functions of the variable $t$ which represent the probabilities of switching the process $\{\mathrm{X}(\mathrm{t}): \mathrm{t} \geq 0\}$ from the state $\mathrm{c}_{\mathrm{i}}$ to the state $\mathrm{e}_{\mathrm{j}}$ $\left(e_{i}, e_{j} \in E_{e} ; i, j=1,2,3,4 ; i \neq j\right)$ in time not longer than $t$, and are described in the following way $[3,7]$ :

$$
\begin{gathered}
\mathrm{Q}_{\mathrm{ij}}(\mathrm{t})=\mathrm{P}\left\{\mathrm{X}\left(\tau_{\mathrm{n}+1}\right)=\right. \\
\left.=\mathrm{e}_{\mathrm{j}}, \tau_{\mathrm{n}+1}-\tau_{\mathrm{n}}<\mathrm{t} \mid \mathrm{X}\left(\tau_{\mathrm{n}}\right)=\mathrm{e}_{\mathrm{i}}\right\}=\mathrm{p}_{\mathrm{ij}} \mathrm{F}_{\mathrm{ij}}(\mathrm{t})
\end{gathered}
$$

where:

$e_{i}, e_{j} \in E_{e}(i, j=1,2,3,4 ; i \neq j)$,

and: $p_{i j}$ is the probability of switching in one step of the homogeneous Markov chain inserted in the process $\{X(t): t \geq 0\}$. $F_{i j}(t)$ is the distribution function of the random variable $T_{i j}$ representing the duration time of the state $c_{i}$ of the process $\{X(t): t \geq 0\}$ on condition that the next state will be $e_{j}$.

The probability $\mathrm{p}_{\mathrm{ij}}$ is interpreted in the following way:

$$
\mathrm{p}_{\mathrm{ij}}=\mathrm{P}\left\{\mathrm{X}\left(\tau_{\mathrm{n}+1}\right)=\mathrm{e}_{\mathrm{j}} \mid \mathrm{X}\left(\tau_{\mathrm{n}}\right)=\mathrm{e}_{\mathrm{i}}\right\}=\lim _{\mathrm{t} \rightarrow \infty} \mathrm{Q}_{\mathrm{ij}}(\mathrm{t})
$$

In this situation solving the problem consist in finding the limiting distribution of the process $\{\mathrm{X}(\mathrm{t}): \mathrm{t} \geq 0\}$ having the following interpretation:

$$
P_{j}=\lim _{t \rightarrow \infty} P\left\{X(t)=e_{j}\right\}, j=\overline{1.4}
$$

This distribution can be calculated using the formula [7]:

$$
P_{j}=\frac{\pi_{j} E\left(T_{j}\right)}{\sum_{k=0}^{3} \pi_{k} E\left(T_{k}\right)}, j=1,2,3,4
$$

where:

$\pi_{\mathrm{j}}=\lim _{\mathrm{n} \rightarrow \infty} \frac{1}{\mathrm{n}} \sum_{\mathrm{k}=1}^{\mathrm{n}} \mathrm{P}\left\{\mathrm{X}\left(\tau_{\mathrm{n}}\right)=\mathrm{e}_{\mathrm{j}} \mid \mathrm{X}(0)=\mathrm{e}_{\mathrm{i}}\right\}$

$\left[\pi_{j} ; j=1,2,3,4\right]-$ the stationary distribution of the Markov chain $\left\{X\left(\tau_{n}\right): n \in N\right\}$ inserted in the process $\{\mathrm{X}(\mathrm{t}): \mathrm{t} \geq 0\}$.

The matrix (5) is the stochastic matrix, therefore this distribution is fulfilled by the following equation system (19) [7]:

$$
\left.\begin{array}{c}
{\left[\pi_{1}, \pi_{2}, \pi_{3}, \pi_{4}\right]\left[\begin{array}{cccc}
0 & 1 & 0 & 0 \\
p_{21} & 0 & p_{23} & 0 \\
0 & p_{32} & 0 & p_{34} \\
0 & 0 & 1 & 0
\end{array}\right]=\left[\pi_{1}, \pi_{2}, \pi_{3}, \pi_{4}\right]} \\
\pi_{1}+\pi_{2}+\pi_{3}+\pi_{4}=1
\end{array}\right\}
$$

After solving the equation system (9) we obtain the following relations according to the formula (8):

$$
\begin{aligned}
& \mathrm{P}_{1}=\frac{\mathrm{p}_{21} \mathrm{p}_{32} \mathrm{E}\left(\mathrm{T}_{1}\right)}{\mathrm{M}} ; \mathrm{P}_{2}=\frac{\mathrm{p}_{32} \mathrm{E}\left(\mathrm{T}_{2}\right)}{\mathrm{M}} ; \\
& \mathrm{P}_{3}=\frac{\mathrm{p}_{23} \mathrm{E}\left(\mathrm{T}_{3}\right)}{\mathrm{M}} ; \mathrm{P}_{4}=\frac{\mathrm{p}_{23} \mathrm{p}_{34} \mathrm{E}\left(\mathrm{T}_{4}\right)}{\mathrm{M}}
\end{aligned}
$$

where:

$\mathrm{M}=\mathrm{p}_{21} \mathrm{p}_{32} \mathrm{E}\left(\mathrm{T}_{1}\right)+\mathrm{p}_{32} \mathrm{E}\left(\mathrm{T}_{2}\right)+\mathrm{p}_{23} \mathrm{E}\left(\mathrm{T}_{3}\right)+\mathrm{p}_{23} \mathrm{p}_{34} \mathrm{E}\left(\mathrm{T}_{4}\right) ;$

$\mathrm{p}_{\mathrm{ij}} \quad-$ probability of switching the process $\{\mathrm{X}(\mathrm{t}): \mathrm{t} \geq 0\}$ from state $e_{i}$ to state $e_{j}\left(e_{i}, e_{j} \in E_{e} ; i, j=1,2,3,4 ; i \neq j\right)$;

(5) $\quad E\left(T_{j}\right)$ - expected value of the random variable $T_{j}(j=1,2,3,4)$ representing the duration time of the state $e_{j} \in E_{e}$ $(j=1,2,3,4)$ of the process $\{X(t): t \geq 0\}$ irrespective of the next state to which this process switches. 
The expected values $E\left(T_{\mathrm{j}}\right)$ are related with the expected values $E\left(T_{i j}\right)$ and the probability $p_{i j}$ in the following way:

$$
E\left(T_{j}\right)=E\left(T_{i}\right)=\sum_{j} p_{i j} E\left(T_{i j}\right), i, j=\overline{1,4} ; i \neq j
$$

Therefore, according to the adopted interpretation of the internal combustion engine operation $[2,10]$, the main engine operation can be defined in the following general way, see (Fig. 4) and formula (7):

$$
\begin{aligned}
\mathrm{D}\left[\tau_{1}, \tau_{9}\right)= & \mathrm{P}_{1} \mathrm{E}_{1} \mathrm{E}\left(\mathrm{T}_{1}\right)+\mathrm{P}_{2} \mathrm{E}_{2} \mathrm{E}\left(\mathrm{T}_{2}\right)+\mathrm{P}_{3} \mathrm{E}_{3} \mathrm{E}\left(\mathrm{T}_{33}\right)+ \\
+\mathrm{P}_{4} \mathrm{E}_{4} \mathrm{E}\left(\mathrm{T}_{4}\right)+\mathrm{P}_{2} \mathrm{E}_{2} \mathrm{E}\left(\mathrm{T}_{2}\right)+\mathrm{P}_{3} \mathrm{E}_{3} \mathrm{E}\left(\mathrm{T}_{3}\right)+ & \\
& +\mathrm{P}_{1} \mathrm{E}_{1} \mathrm{E}\left(\mathrm{T}_{1}\right)+\mathrm{P}_{2} \mathrm{E}_{2} \mathrm{E}\left(\mathrm{T}_{2}\right)
\end{aligned}
$$

The main engine operation defined by formula (12) takes place when we can assume that the changes of the propeller characteristic, resulting from changes of sailing conditions, do not affect considerably the changes of energy conversion in the engine working spaces, i.e. we can assume that the energy $\mathrm{E}=\mathrm{idem}$.

When changes of the energy E are larger and cannot be omitted, the formula (12) is to be modified by introducing the average value of this energy, which, as the random variable, is the statistics $\overline{\mathrm{E}}$. Then the operation will be defined in the following way:

$$
\begin{gathered}
\overline{\mathrm{D}}\left[\tau_{1}, \tau_{9}\right)=\mathrm{P}_{1} \overline{\mathrm{E}}_{1} \mathrm{E}\left(\mathrm{T}_{1}\right)+\mathrm{P}_{2} \overline{\mathrm{E}}_{2} \mathrm{E}\left(\mathrm{T}_{2}\right)+\mathrm{P}_{3} \overline{\mathrm{E}}_{3} \mathrm{E}\left(\mathrm{T}_{3}\right)+ \\
+\mathrm{P}_{4} \overline{\mathrm{E}}_{4} \mathrm{E}\left(\mathrm{T}_{4}\right)+\mathrm{P}_{2} \overline{\mathrm{E}}_{2} \mathrm{E}\left(\mathrm{T}_{2}\right)+\mathrm{P}_{3} \overline{\mathrm{E}}_{3} \mathrm{E}\left(\mathrm{T}_{3}\right)+ \\
+\mathrm{P}_{1} \overline{\mathrm{E}}_{1} \mathrm{E}\left(\mathrm{T}_{1}\right)+\mathrm{P}_{2} \overline{\mathrm{E}}_{2} \mathrm{E}\left(\mathrm{T}_{2}\right)
\end{gathered}
$$

A more accurate definition of the operation requires introducing probabilities $\mathrm{P}_{\mathrm{j}}(\mathrm{j}=1, \ldots, 4)$ given by formula (20) to equations (12) and (13).

Particular probabilities $\mathrm{P}_{\mathrm{j}}(\mathrm{j}=1, \ldots, 4)$ have the following interpretations:

$$
\begin{aligned}
& \mathrm{P}_{1}=\lim _{\mathrm{t} \rightarrow \infty} \mathrm{P}\left\{\mathrm{X}(\mathrm{t})=\mathrm{e}_{1}\right\}, \mathrm{P}_{2}=\lim _{\mathrm{t} \rightarrow \infty} \mathrm{P}\left\{\mathrm{X}(\mathrm{t})=\mathrm{e}_{2}\right\}, \\
& \mathrm{P}_{3}=\lim _{\mathrm{t} \rightarrow \infty} \mathrm{P}\left\{\mathrm{X}(\mathrm{t})=\mathrm{e}_{3}\right\}, \mathrm{P}_{4}=\lim _{\mathrm{t} \rightarrow \infty} \mathrm{P}\left\{\mathrm{X}(\mathrm{t})=\mathrm{e}_{4}\right\}
\end{aligned}
$$

The probability $\mathrm{P}_{1}$ can be interpreted as the probability of engine load according to the partial power characteristic, and the three remaining probabilities $\mathrm{P}_{2}, \mathrm{P}_{3}$ and $\mathrm{P}_{4}$ can have similar interpretations referring to the operating power, nominal power, and maximal power characteristics, respectively.

Obtaining the (obviously approximate) values of the probabilities $P_{j}(j=1,2,3,4)$ requires valuating $p_{i j}$ and $E\left(T_{j}\right)$.

Valuating the probabilities $\mathrm{p}_{\mathrm{ij}}$ and the expected values $E\left(T_{\mathrm{j}}\right)$ is possible when we have the realisation $\mathrm{x}(\mathrm{t})$ of the process $\{X(t): t \geq 0\}$ in a relatively long time interval of investigations, i.e. for $\mathrm{t} \in\left[0, \mathrm{t}_{\mathrm{b}}\right]$, where $\mathrm{t}_{\mathrm{b}}>>0$. Then we can obtain numbers $\mathrm{n}_{\mathrm{ij}}(\mathrm{i}, \mathrm{j}=1,2,3,4 ; \mathrm{i} \neq \mathrm{j})$, which represent the number of changes from the state $e_{i}$ to the state $e_{j}$ in the relatively long time.

The estimator of the highest likelihood of the probability of change $\mathrm{p}_{\mathrm{ij}}$ is the statistics: [7]

$$
\hat{P}_{i j}=\frac{N_{i j}}{\sum_{j} N_{i j}}, i \neq j ; i, j=1,2,3,4
$$

the value:

$$
\hat{P}_{i j}=\frac{N_{i j}}{\sum_{j} N_{i j}}
$$

of which is the assessment of the unknown probability $p_{i j}$ of switching the process $\{\mathrm{X}(\mathrm{t}): \mathrm{t} \geq 0\}$ from the state $\mathrm{e}_{\mathrm{i}}$ to the state $e_{j}$.
From the abovementioned realisation $\mathrm{x}(\mathrm{t})$ we can also obtain realisations $\mathrm{t}_{\mathrm{ij}}{ }^{(\mathrm{m})}, \mathrm{m}=1,2, \ldots, \mathrm{n}_{\mathrm{ij}}$ of the random variables $\mathrm{T}_{\mathrm{j}}$. The application of point estimation provides opportunities for easy assessment of $\mathrm{E}\left(\mathrm{T}_{\mathrm{j}}\right)$ as the arithmetic mean of the realisation $\mathrm{t}_{\mathrm{ij}}(\mathrm{m})$.

The expected value of energy in formula (12) is the observed value of the statistics $\overline{\mathrm{E}}_{\mathrm{k}}(\mathrm{k}=1,2,3,4)$. Obviously, this statistics is the random variable $[1,7]$ having the following general formula:

$$
\overline{\mathrm{E}}_{\mathrm{k}}=\frac{1}{\mathrm{n}} \sum_{\mathrm{i}=1}^{\mathrm{n}} \mathrm{E}_{\mathrm{ki}}
$$

where:

$\mathrm{E}_{\mathrm{ki}}$ - random variables having the same (arbitrary) distributions, with the same expected value $\mathrm{E}\left(\mathrm{E}_{\mathrm{ki}}\right)=$ $=\mathrm{m}_{1 \mathrm{ki}}$ and variance:

$$
\mathrm{D}^{2}\left(\mathrm{E}_{\mathrm{ki}}\right)=\sigma_{\mathrm{ki}}^{2} \neq 0
$$

This way the random variable $\overline{\mathrm{E}}_{\mathrm{k}}$ (statistics) is the arithmetic mean of $\mathrm{n}$ independent random variables $\mathrm{E}_{\mathrm{ki}}$ having the same distributions. The expected value and the variance of the random variable $\overline{\mathrm{E}}_{\mathrm{k}}$ are given by the relations $[1,14]$ :

$$
\begin{gathered}
\mathrm{E}\left(\overline{\mathrm{E}}_{\mathrm{k}}\right)=\mathrm{E}\left(\mathrm{E}_{\mathrm{k}}\right)=\mathrm{m}_{1 \mathrm{k}}, \\
\mathrm{D}^{2}\left(\mathrm{E}_{\mathrm{kn}}\right)=\frac{1}{\mathrm{n}} \mathrm{D}^{2}\left(\mathrm{E}_{\mathrm{ki}}\right)=\frac{\delta_{\mathrm{k}}^{2}}{\mathrm{n}}
\end{gathered}
$$

It results from the Lindeberg-Levy theorem [1] that the random variable $\overline{\mathrm{E}}_{\mathrm{k}}$ has the asymptotically normal distribution $\mathrm{N}\left(\mathrm{m}_{1 \mathrm{k}}, \sigma_{\mathrm{k}} / \sqrt{\mathrm{n}}\right)$ irrespective of the nature of the random variable $\mathrm{E}_{\mathrm{k}}$. That means that the arithmetic mean of $\mathrm{n}$ independent random variables $\mathrm{E}_{\mathrm{ki}}$ having an arbitrary but the same distribution and the same expected value, $\mathrm{E}\left(\mathrm{E}_{\mathrm{ki}}\right)=\mathrm{m}_{1 \mathrm{k}}$ and the variance $\mathrm{D}^{2}\left(\mathrm{E}_{\mathrm{ki}}\right)=\sigma_{\mathrm{k}}^{2}$, has the asymptotically normal distribution $\mathrm{N}\left(\mathrm{m}_{1 \mathrm{k}}, \sigma_{\mathrm{k}} / \sqrt{\mathrm{n}}\right)$.

Applying the proposed methodology to the analysis of energy changes during the main engine operation seems attractive due to the fact that the convergence of the distribution of the statistics $\overline{\mathrm{E}}_{\mathrm{k}}$ to the normal distribution $\mathrm{N}\left(\mathrm{m}_{1 \mathrm{k}}, \sigma_{\mathrm{k}} / \sqrt{\mathrm{n}}\right)$ is very fast and we can use it for all $n \geq 4$, i.e. always in practice [1].

When the value $\sigma_{\mathrm{k}}$ is known, taking into account the distribution $\mathrm{N}\left(\mathrm{m}_{1 \mathrm{k}}, \sigma_{\mathrm{k}} / \sqrt{\mathrm{n}}\right)$ of the statistics $\overline{\mathrm{E}}_{\mathrm{k}}$ we can calculate the confidence interval for the unknown expected value $\mathrm{m}_{\mathrm{k} 1}=$ $\mathrm{E}\left(\mathrm{E}_{\mathrm{k}}\right)$ using the formula $[1,10]$ :

$$
\mathrm{P}\left\{\overline{\mathrm{e}}_{\mathrm{k}}-\mathrm{y}_{\alpha} \frac{\sigma_{\mathrm{k}}}{\sqrt{\mathrm{n}}} \leq \mathrm{E}\left(\mathrm{E}_{\mathrm{k}}\right) \leq \overline{\mathrm{e}}_{\mathrm{k}}+\mathrm{y}_{\alpha} \frac{\sigma_{\mathrm{k}}}{\sqrt{\mathrm{n}}}\right\}=\beta
$$

where:

$\beta-$ confidence level,

$\mathrm{y}_{\alpha}-$ standardised variable of the normal distribution, which corresponds to the confidence level $\beta=1-\alpha$ $(\alpha$ - significance level),

$\overline{\mathrm{e}}_{\mathrm{k}}-$ value of the statistics $\overline{\mathrm{E}}_{\mathrm{k}}$, which is the arithmetic mean of the performed measurements.

In experimental practice, as a rule, the value $\sigma_{\mathrm{k}}$ is not known, but it can be evaluated using the formula $[1,14]$ :

$$
\mathrm{s}_{\mathrm{k}}=\sqrt{\frac{1}{\mathrm{n}-1} \sum_{\mathrm{i}=1}^{\mathrm{n}}\left(\mathrm{e}_{\mathrm{ki}}-\overline{\mathrm{e}}_{\mathrm{k}}\right)^{2}}
$$

Since the statistics $\overline{\mathrm{E}}_{\mathrm{k}}$ has always the asymptotically normal distribution $\mathrm{N}\left(\mathrm{m}_{1 \mathrm{k}}, \sigma_{\mathrm{k}} / \sqrt{\mathrm{n}}\right)$, and its convergence to the normal distribution $\mathrm{N}\left(\mathrm{m}_{1}, \sigma\right)$ is very fast, we can assume in practice that 
the investigated energy $\mathrm{E}_{\mathrm{k}}$ has normal distribution $\mathrm{N}\left(\mathrm{m}_{1 \mathrm{k}}, \sigma_{\mathrm{k}}\right)$. It is noteworthy, however, that adopting the above assumption is not a limitation in experimental practice, as the statistics $\overline{\mathrm{E}}_{\mathrm{k}}$ has always statistically normal distribution $\mathrm{N}\left(\mathrm{m}_{1 \mathrm{k}}, \sigma_{\mathrm{k}} / \sqrt{\mathrm{n}}\right)$. Moreover, the convergence of this distribution to the normal distribution is very fast [3]. Therefore the random variable:

$$
\frac{\overline{\mathrm{E}}_{\mathrm{k}}-\mathrm{E}\left(\mathrm{E}_{\mathrm{k}}\right)}{\mathrm{s}_{\mathrm{k}}} \sqrt{\mathrm{n}-1}
$$

has the t-Student distribution with $\mathrm{k}=\mathrm{n}-1$ degrees of freedom $[1,10]$. That means that the confidence interval for the unknown expected value $\mathrm{E}\left(\mathrm{E}_{\mathrm{k}}\right)$ of the random variable $\mathrm{E}_{\mathrm{k}}$ can be calculated using the formula $[1,10]$ :

$\mathrm{P}\left\{\overline{\mathrm{e}}_{\mathrm{k}}-\mathrm{t}_{\alpha, \mathrm{n}-1} \frac{\mathrm{s}_{\mathrm{k}}}{\sqrt{\mathrm{n}}-1} \leq \mathrm{E}\left(\mathrm{E}_{\mathrm{k}}\right) \leq \overline{\mathrm{e}}_{\mathrm{k}}+\mathrm{t}_{\alpha, \mathrm{n}-1} \frac{\mathrm{s}_{\mathrm{k}}}{\sqrt{\mathrm{n}-1}}\right\}=\beta$

In practice, the formula (19) is more applicable for assessing the energy changes during engine operation in real conditions of ship sailing than the commonly used formula (15), as it not only reflects the randomness of the results obtained in operating conditions, but also determines the error in estimating the expected value of the energy converted in the engine in its particular states. This error, which in the present case is equal to $1-\beta$, is the not covering of the expected value $\mathrm{E}\left(\mathrm{E}_{\mathrm{k}}\right)$ by the confidence interval given by the formula (19).

The application of the estimation in intervals makes it possible to determine the expected value $E\left(E_{k}\right)$ in the form of an interval with random limits, which means that the following inequality is to be fulfilled with probability $\beta$ :

$$
\mathrm{E}_{\mathrm{d}} \leq \mathrm{E}\left(\mathrm{E}_{\mathrm{k}}\right) \leq \mathrm{E}_{\mathrm{g}}
$$

It results from the inequality (20) that the main engine operation which can be considered safe can be assessed in the following way, according to formula (13):

$$
\begin{gathered}
\overline{\mathrm{D}}\left[\tau_{1}, \tau_{9}\right)=\mathrm{P}_{1} \mathrm{E}_{1 \mathrm{~d}} \mathrm{E}\left(\mathrm{T}_{1}\right)+\mathrm{P}_{2} \mathrm{E}_{2 \mathrm{~d}} \mathrm{E}\left(\mathrm{T}_{2}\right)+\mathrm{P}_{3} \mathrm{E}_{3 \mathrm{~d}} \mathrm{E}\left(\mathrm{T}_{3}\right)+ \\
+\mathrm{P}_{4} \mathrm{E}_{4 \mathrm{~d}} \mathrm{E}\left(\mathrm{T}_{4}\right)+\mathrm{P}_{2} \mathrm{E}_{2 \mathrm{~d}} \mathrm{E}\left(\mathrm{T}_{2}\right)+\mathrm{P}_{3} \mathrm{E}_{3 \mathrm{~d}} \mathrm{E}\left(\mathrm{T}_{3}\right)+ \\
\quad+\mathrm{P}_{1} \mathrm{E}_{1 \mathrm{~d}} \mathrm{E}\left(\mathrm{T}_{1}\right)+\mathrm{P}_{2} \mathrm{E}_{2 \mathrm{~d}} \mathrm{E}\left(\mathrm{T}_{2}\right)
\end{gathered}
$$

On the other hand, the optimistic engine operation can be assessed, according to formula (13), as:

$$
\begin{gathered}
\overline{\mathrm{D}}\left[\tau_{1}, \tau_{9}\right)=\mathrm{P}_{1} \mathrm{E}_{1 \mathrm{~g}} \mathrm{E}\left(\mathrm{T}_{1}\right)+\mathrm{P}_{2} \mathrm{E}_{2 \mathrm{~g}} \mathrm{E}\left(\mathrm{T}_{2}\right)+\mathrm{P}_{3} \mathrm{E}_{3 \mathrm{~g}} \mathrm{E}\left(\mathrm{T}_{3}\right)+ \\
+\mathrm{P}_{4} \mathrm{E}_{4 \mathrm{~g}} \mathrm{E}\left(\mathrm{T}_{4}\right)+\mathrm{P}_{2} \mathrm{E}_{2 \mathrm{~g}} \mathrm{E}\left(\mathrm{T}_{2}\right)+\mathrm{P}_{3} \mathrm{E}_{3 \mathrm{~g}} \mathrm{E}\left(\mathrm{T}_{3}\right)+ \\
\quad+\mathrm{P}_{1} \mathrm{E}_{1 \mathrm{~g}} \mathrm{E}\left(\mathrm{T}_{1}\right)+\mathrm{P}_{2} \mathrm{E}_{2 \mathrm{~g}} \mathrm{E}\left(\mathrm{T}_{2}\right)
\end{gathered}
$$

If necessary, processes of this type with a larger number of states $\mathrm{e}_{\mathrm{i}}, \mathrm{i}=1,2,3, \ldots \mathrm{K}$ can be investigated. Taking theoretically into account these needs, we can most generally discuss the process $\{X(t): t \geq 0\}$ with the set of states $E_{e K}=\left\{e_{1}, e_{2}, e_{3}, \ldots\right.$, $\left.\mathrm{e}_{\mathrm{K}}\right\}$. This process will be fully defined if, like in previous cases, a formula is given for the functional matrix:

$$
\mathrm{Q}_{\mathrm{ij}}=\left[\mathrm{Q}_{\mathrm{ij}}(\mathrm{t})\right] \mathrm{i}, \mathrm{j}=1,2,3, \ldots, \mathrm{K}
$$

and the initial distribution:

$$
\mathrm{P}_{\mathrm{i}}=\mathrm{P}\left\{\mathrm{X}(0)=\mathrm{e}_{\mathrm{i}}\right\} \mathrm{i}=1,2,3, \ldots, \mathrm{K}
$$

For this generalised case the matrix of the process $\{\mathrm{X}(\mathrm{t}): \mathrm{t} \geq 0\}$ is the following:

$$
\mathbf{Q}(\mathbf{t})=\left[\begin{array}{ccccccc}
0 & \mathrm{Q}_{12}(\mathrm{t}) & 0 & \ldots & 0 & 0 & 0 \\
\mathrm{Q}_{21}(\mathrm{t}) & 0 & \mathrm{Q}_{23}(\mathrm{t}) & \ldots & 0 & 0 & 0 \\
\ldots & \ldots & \ldots & \ldots & \ldots & \ldots & \ldots \\
0 & 0 & 0 & \ldots \mathrm{Q}_{\mathrm{K}-1 \mathrm{~K}-2}(\mathrm{t}) & 0 & \mathrm{Q}_{\mathrm{K}-1 \mathrm{~K}}(\mathrm{t}) \\
0 & 0 & 0 & \ldots & 0 & \mathrm{Q}_{\mathrm{KK}-1}(\mathrm{t}) & 0
\end{array}\right]
$$

and its initial distribution has the form:

$$
P_{i}=P\left\{X(0)=e_{i}\right\}=\left\{\begin{array}{l}
1 \text { for } i=1 \\
0 \text { for } i=2,3, \ldots, K
\end{array}\right.
$$

Consequently, $\mathrm{P}\left\{\mathrm{X}(0)=\mathrm{e}_{1}\right\}=1$.

Like in previous analyses, we have to assess the limiting distribution of the process [7]:

$$
P_{j}=\frac{\pi_{j} E\left(T_{j}\right)}{\sum_{k=1}^{K} \pi_{k} E\left(T_{k}\right)}, j=1,2, \ldots, K
$$

Using the same procedure as in previous cases we arrive at the relation:

$$
P_{j}=\frac{\left[\prod_{k=2}^{j} \frac{\left(1-p_{k-1 k-2}\right)}{p_{k k-1}}\right] E\left(T_{j}\right)}{E\left(T_{1}\right)+\left[\sum_{j=2}^{K} \prod_{k=2}^{j} \frac{\left(1-p_{k-1 k}\right)}{p_{k k-1}}\right] E\left(T_{j}\right)} j=2,3, \ldots, K
$$

It results from formula (27) that, for instance, the probability of engine load resulting from the appearance of the state $e_{1}$ can be calculated as [7]:

$$
P_{1}=\frac{E\left(T_{1}\right)+\left[\sum_{j=2}^{K} \prod_{k=2}^{j} \frac{\left(1-p_{1}\right)}{\left.p_{k k-1 k-2}\right)}\right] E\left(T_{j}\right)}{p_{k}}
$$

The presented considerations reveal that after adopting the interpretation of the operation in the here proposed version and making use of the theory of semi-Markov processes we can determine the operation of marine main engines in probabilistic formulation, which is more adequate than the deterministic formulation, as it reflects random conditions of operation of engines of this type.

\section{REMARKS AND CONCLUSIONS}

- The article presents the probabilistic method for evaluating the operation of an internal combustion engine used as the main engine on a ship. This method can be applied to an arbitrary piston internal combustion engine of both spark-ignition and compression-ignition type. The method takes it into account stochastic nature of energy conversion processes observed during engine operation. It was proved that a very useful model for investigating those processes is the model having the form of a stochastic process which is discrete in states and continuous in time. The analyses presented in the article reveal that this model can be the semi-Markov process which has the abovementioned features.

- The operation of the internal combustion engine was interpreted as generation of the required energy in a given time and its delivery (transmission) to the receiver. That means that when analysing the operation of these engines in given time and taking into account both the energy generated by these engines and time of its generation, we can compare (in a valuating formulation) this operation to a physical quantity which has a numerical value and the measure unit called joule-second [joule $\times$ second].

When analysing energy related qualities of internal combustion engines we should analyse their whole 
operation, and not only their work, as the engine operation includes not only the energy conversion into work, but also into heat.

- The process of changes of energy states during the operation of an arbitrary diesel engine is a random process with continuous, positive and limited realisations.

- The models of changes of energy states may refer to the operation of an arbitrary engine, and include various numbers and interpretations of energy states. In each case, however, a model can be constructed in the form of a semiMarkov process, continuous in time and discrete in states, i.e. having a limited number of states.

- The developed semi-Markov model of the process of energy state changes during the main engine operation is the process with limited number of states and continuous in time.

Another approach to investigating the energy converted in the main engine and transmitted to the propeller screw was also proposed. This approach consists in considering this energy a random variable. The applicability of the Lindeberg-Levy theorem was proved which says that the statistics created based on the results of the investigations of a given energy is the random variable having the asymptotically normal distribution, irrespective of the nature of the random variable representing this energy. This enables using the estimation in intervals to evaluate the unknown expected value of the random variable, which can be the energy converted in the main engine and transmitted to the propeller screw during engine operation.

- The application of the estimation in intervals to the evaluation of engine operation has made it possible to assess its value in an optimistic version (22) and a safe version (21).

\section{BIBLIOGRAPHY}

1. Firkowicz S.: Statistic evaluation of quality and reliability of electron tubes (in Polish). WNT, Warszawa 1963.

2. Girtler J.: a method for evaluating the performance of a marine piston internal combustion engine used as the main engine on a ship during its voyage in different sailing conditions Polish Maritime Research. Vol. 17, iss. 4(67), 2010.

3. Girtler J.: Physical aspect of application and usefulness of semiMarkovian processes for modelling the processes occurring in operational phase of technical objects. Polish Maritime Research. 2004 nr 3(41), vol. 11, pp. 25-30.

4. Girtler J.: Possibility of valuation of operation of marine diesel engines. Journal of POLISH CIMAC, Vol. 4, No 1, 2009.
5. Girtler J.: Energy-based aspect of operation of diesel engine. COMBUSTION ENGINES No 2/2009 (137).

6. Girtler J.: Conception of valuation of combustion engine operation. Journal of KONES. Powertrain and Transport. Editorial Office Institute of Aeronautics BK, Warsaw 2008.

7. Grabski F.: Theory of semi-Markov processes of operation of technical objects (in Polish). ZN AMW nr 75A, Gdynia 1982.

8. Gribbin J.: In Search of Schrödinger's Cat Quantum Physics Reality. (Polish issue). Zysk i S-ka Wydawnictwo s.c. Poznań 1997.

9. Helwitt P.G.: Physics around us (in Polish). PWN, Warszawa 2001.

10.Pawłowski Z.: Mathematical statistics (in Polish). PWN, Warszawa 1980.

11.Piotrowski I., Witkowski K.: Operation of marine internal combustion engines (in Polish). AM, Gdynia 2002.

12.Rosłanowski J.: Identification of ships propulsion engine operation by means of dimensional analysis. Journal of POLISH CIMAC, Vol 4, No 1, 2009.

13.Rudnicki J.: On making into account value of operational applied to ship main propulsion engine as an example. Journal of POLISH CIMAC, Vol 4, No 1, 2009.

14.Volk W.: Applied statistics for engineers (in Polish). WNT, Warszawa 1965.

15.Wajand J.A.: Compression-ignition engine (in Polish). WNT, Warszawa 1988.

16.Włodarski J.K.: Operating states of marine internal combustion engines (in Polish). WSM, Gdynia 1998.

17. Wojnowski W.: Marine internal-combustion power plants, Pt I. (in Polish). AMW, Gdynia 1999.

18. Encyclopaedia of contemporary physics (in Polish). Collective work. Editor: Redakcja Nauk Matematyczno-Fizycznych i Techniki Zespołu Encyklopedii i Słowników PWN. PWN, Warsaw 1983.

19. Scientific and technical lexicon with supplement (in Polish). Collective work. Editor: Zespół redaktorów Działu Słownictwa Technicznego WNT. WNT, Warsaw 1989.

\section{CONTACT WITH THE AUTHOR}

Jerzy Girtler, Prof.

Faculty of Ocean Engineering and Ship Technology

Gdansk University of Technology

Narutowicza 11/12

80-233 Gdansk, POLAND

tel.: (+48 58) 347-24-30; fax: (+48 58) 347-19-81

e-mail:.jgirtl@pg.gda.pl 